\title{
FOREST CANOPY DENSITY ASSESSMENT USING HIGH RESOLUTION LISS-4 DATA IN YAMUNANAGAR DISTRICT, HARYANA
}

\author{
K.E. Mothi Kumar ${ }^{1}$, Ritesh Kumar ${ }^{1, *}$, Parmod Kumar ${ }^{1}$, Sattyam $^{1}$, Vikash Sihag ${ }^{1}$, Partibha $^{1}$, Kaptan Singh $^{1}$, Seema Rani ${ }^{1}$, Poonam \\ Sharma $^{1}$,R.S. Hooda ${ }^{1}$, T. P. Singh ${ }^{2}$
}

${ }^{1}$ Haryana Space Applications Centre, Hisar, Haryana, India - ritesh.kumar05@ gmail.com

${ }^{2}$ Conservator of Forests (Planning and MIS), Haryana Forest Department, Van Bhawan, Panchkula

\section{Commission V, SS: Natural Resources Management}

KEY WORDS: Forest Canopy Density (FCD), Afforestation, LISS-4, Notified forest area, Forest Quality, AVI, BSI, CSI, ITTO

\begin{abstract}
:
Forest plays an important role not only in providing ecological services but also economic goods to human beings. However, with increase in population there is a wide gap between demand and supply of these goods and services. This has lead to reduction in forest cover which needs to be taken care on regular time interval. To manage the existing forest area and also to increase the forest cover Forest Canopy Density (FCD) methodology is the main factor which was given by International Tropical timber Organization (ITTO). High resolution remote sensing LISS-4 data gives us chance to assess the quality of forest in terms of FCD as Rikimaru et al (1999) stated that FCD is one important parameter to assess forest cover quality. High resolution LISS-4 data analysis for FCD was never attempted before. Authors here attempted to assess the FCD utilizing methodology adopted by Rikimaru (1999), Huang (2001), Azizia (2008). The adopted methodology is one of the most efficient and cost effective way to derive the FCD. For this study Resourcesat-2 LISS-4 post monsoon data of year 2017 for Yamunanagar district was used to assess FCD within notified forest boundary. Notified forest boundaries at cadastral level prepared previously by Haryana Space Applications Centre (HARSAC) was used. The degree of forest canopy density is expressed in percentages: i.e. <10\% FCD (scrub land), 10-20\% (Open Forest-I), 20-40\% (Open Forest-II), 40-60\% (Moderate Dense), 60-80\% (Medium Dense) and $>80 \%$ (Highly Dense). Forest Canopy Density was based on three indices i.e. Advanced Vegetation Index (AVI), Bare Soil Index (BSI) and Canopy Shadow Index (CSI). Accuracy assessment was done based on ground data and comparison with Coterminous Google Earth imagery and it was found that the devised methodology has achieved overall accuracy of 93\% with kappa coefficient of 0.9153 . The result shows that maximum forest area in Yamunanagar district is in medium dense FCD category which is approximately 23948.08 acres. This study tells us that $24.2 \%$ of the total forest area is under scrub land and open forest which should be focussed for activities in working plan to increase the forest cover. This paper highlights the utility of high resolution satellite data for monitoring and management of forest and improvement in its quality. This attempt provided large scale $(1: 10,000)$ maps to the forest managers to better equip them in planning for afforestation, reforestation and rehabilitation of water logged areas, environment management and their future aspect.
\end{abstract}

\section{INTRODUCTION}

Historically our communities have always lived in harmony with nature, and participation of community in protection and management of common property resources has been a tradition. Forest serves as backbone of all the human activities and it provides primary goods for almost all the sectors. But fast growing population has increased the demand of forest goods which has led to the reduction in the forest area. To conserve forest various policies have been framed. The revised National Forest Policy (Ministry of Environment, Forest and Climate change, 1988) has set a goal that one third of the country area should be under forest and tree cover. To promote sustainable development of forest resources in the State, Haryana Government framed its own Forest Policy (Haryana Forest Department, 2006) with the goal of achieving 20\% Forest and Tree Cover in the state in a phased manner by 2020. Forest canopy Density (FCD) is the main factor while planning Afforestation, reforestation and rehabilitation of water logged areas. Forest Canopy not only determines the quality of forests present but also helps in scientific studies related to land management and conservation of resources. Initially when high resolution satellite imagery was not available, FCD mapping was done from field surveys using different techniques (Korhonen et. al.2006). Since the traditional field based measurements of forest canopy are time consuming and are not cost effective and also the accuracy was low (Fiala et al.2006), satellite data based GIS techniques have been devised to estimate the forest canopy density quickly and accurately. The repetitive coverage of satellite remote sensing with various spatial and temporal scales offers the cost effective means of assessing the environmental parameters and impact of the developmental processes. The repetitive nature of spatial data provides excellent capability to monitor ecosystem composition, impact of management and degradation processes. The integrated information derived from the satellite data set assists in evolution of appropriate action plans for initiating sustainable development (Rao, 1996). Formula used for calculating the indices vary according to the sensors as for Landsat TM data (Rikimaru 1999) and for ETM+ data formula for calculating the indices is different (Huang 2001). The FCD-Mapper contains the algorithms and other formulas utilized to compute values of the several indices contained in the Forest Canopy Density Mapping Model for the analysis of satellite imagery data. The canopy density is calculated in percentage for each pixel, this model requires less information of ground truth (Rikimaru 1999).

\footnotetext{
* Corresponding Author
} 


\section{STUDY AREA}

Yamunanagar district is located between $29^{\circ} 55^{\prime}$ to $30^{\circ} 31$ North latitudes and $77^{\circ} 00^{\prime}$ to $77^{\circ} 35^{\prime}$ East longitudes with total area of 1756 square Kilometres. Yamunanagar is a northern district of Haryana State and borders with Uttar Pradesh on the east, with Himachal Pradesh on the north, with Ambala district of Haryana on the west and with Karnal district of Haryana on south. The district has shivalik hills and foot hill rolling plain in the north and north- east, and flood - plain along the Yamuna River in the east and south-east. Important rivers/ streams of the district are Yamuna, Saraswati, Chautang, Rakshi, Somb, Boll etc. Most of the forest area is located on the northern side of the district onto the Shivalik range. Also some part of forest is under agro forestry with Poplar plantations. Acacia arabia, Populus species, Eucalyptus species, Polyalthia longifolia, Cassia siamea, Senegelia catechu, Tectona grandis are the dominant species that are found in Yamunanagar district. The location map of study area is shown in Figure 1.

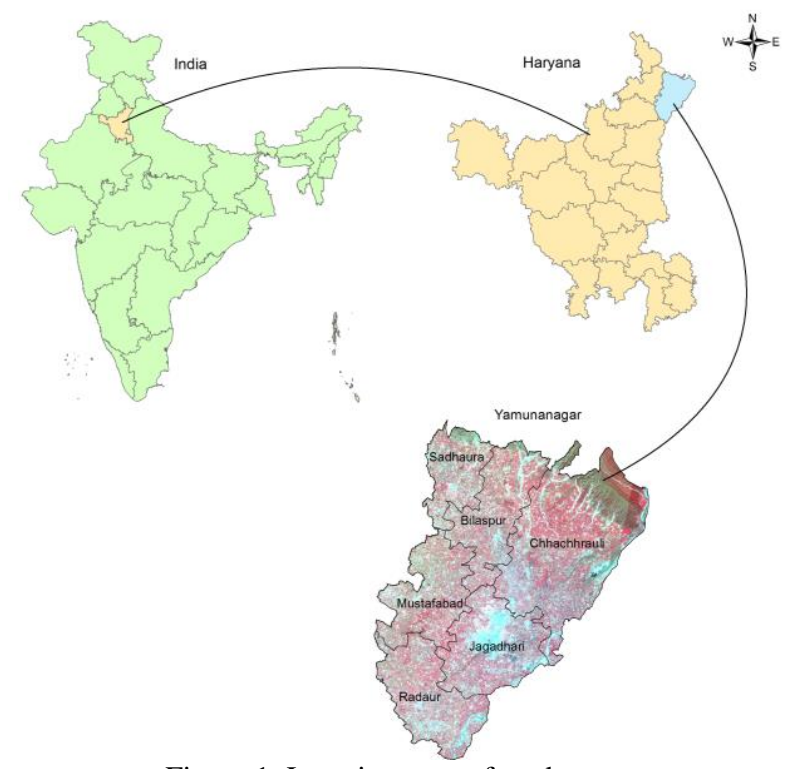

Figure 1. Location map of study area

\section{DATA AND METHODOLOGY}

Post- monsoon Resourcesat 2 LISS-4 data include the scenes of 95-49-D, 95-50-B and 96-50-A (Path-Row-Sub scene) of year 2017 in this research with cadastral level notified forest boundaries.

3.1 Radiometric correction: Adjacency effect reduces the surface contrast by reducing the top of atmospheric radiance over the bright pixels and increases the brightness over the dark pixels (Sharma et. al., 2008). The correction was done on all the scenes of LISS-4 images so that path radiance and noise can be removed from the data and is ready to be used in the FCD model. For this the images were converted from DN to atsensor radiance image using the formula given in Equation 1.

$$
L_{\lambda}=\frac{S R_{k} \times D N}{D N_{\max }}
$$

Where, $\quad \mathrm{SR}_{\mathrm{k}}=$ Saturation radiance of $\mathrm{k}^{\text {th }}$ band $\mathrm{DN}_{\max }=$ Maximum possible value of pixel.
The at-sensor radiance images were further converted to atsensor reflectance image using formula given in Equation 2.

$$
R_{\text {sensor }}=\frac{L_{\lambda} \times \pi \times d^{2}}{E_{\operatorname{sun}} \times \cos \theta_{z}}
$$

Where,

$$
\begin{aligned}
& \text { pi }=3.14159 \\
& R_{\text {sensor }}=\text { reflectance at the sensor } \\
& \mathbf{L}_{\lambda}=\text { spectral radiance at the sensor's aperture } \\
& E_{\text {sun }}=\text { mean solar exo-atmospheric irradiance, } \\
& \theta_{z}=\text { solar zenith angle } \\
& d=\text { earth-sun distance }
\end{aligned}
$$

The at sensor reflectance images were co-registered with orthorectified Worldview-2 data so that the cadastral level forest boundaries which was prepared earlier on World-view dataset was overlaid on LISS-4 images. Cadastral forest boundaries were delineated through extraction of parcels registered for forest areas and their associated characterization (forest/nonforest) based on the land cover characteristics from high resolution satellite data (Mothi Kumar et. al., 2014).

Forest Canopy Density model was prepared which utilizes three indices. These three indices when integrated calculate the canopy density in percentage for each pixel. The flow chart of the procedure is illustrated in the Figure 2.

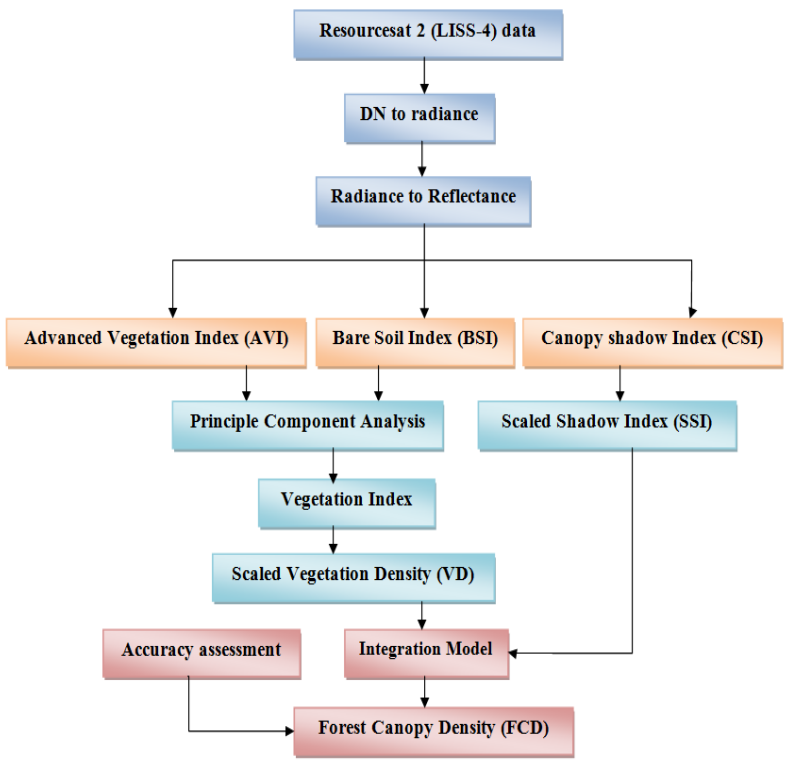

Figure 2. Flow chart of methodology

3.2 Advanced Vegetation Index (AVI): Normalized Difference Vegetation Index (NDVI) was unable to highlights the minor changes in canopy density. So, AVI was used because this includes the power degree of infra red which highlights the vegetation categories. i.e. forest cover and grassland. AVI increases as the vegetation cover increase which is calculated (Rikimaru, 1999) using Equation 3.

$$
A V I=\sqrt[3]{\left(B 4 \times\left(D N_{\max }-B 3\right) \times(B 4-B 3)+1\right)}
$$

3.3 Bare Soil index (BSI): It increases as the bare soil exposure degree of ground to sunlight increases (Azizi et.al., 2008). This is calculated using Equation 4.

$$
B S I=\frac{((B 4+B 2)-B 3)}{((B 4+B 2)+B 3)}
$$


3.4 Canopy Shadow Index (CSI): Mature forest shows high degree of shadow in comparison to the young aged forest cover (Azizia et.al. 2008). SI is calculated based on Equation 5.

$$
C S I=\sqrt{\left(\left(D N_{\max }-B 2\right) \times\left(D N_{\max }-B 3\right)\right)}
$$

Where,

$\mathrm{DN}_{\max }=$ maximum possible pixel value

B2 (green), B3 (red), B4 (near infrared) are the bands of LISS-4 data.

Now, First component of Principle Component Analysis is calculated using AVI and BSI. Then values are calibrated to calculate Vegetation Density (VD). Scaled Shadow Index (SSI) is calculated by calibrating the values of Canopy shadow index (CSI).

3.5 Forest Canopy Density: Integration of VD and SSI means transformation for forest canopy density value. Both parameter are dimensionless and has percentage scale unit of density. It is possible to synthesize both indices safely by means of corresponding scale and units of each. Forest Canopy Density (\%) for each pixel is calculated by using the Equation 6 (Rikimaru, 1999).

$$
F C D=\sqrt{(V D \times S S I+1)}-1
$$

\section{RESULT AND DISCUSSION}

Majority of dense forest area in Haryana lies in Panchkula and Yamunanagar district. Approximately $10 \%$ area out of total area is under forest in Yamunanagar district, majority of which lies in Chhachhrauli block which is in the northern part along the Shivalik range which comes under Kalesar National Park.

On moving from mountainous region to plain area FCD starts decreasing. There are few areas of high density in plain region because of agro forestry. The lowest FCD category i.e. scrub land is also found along the river and natural drains. Based upon present study, FCD map of Yamunanagar district is shown in Figure 3.

After FCD calculation, ground validation is also carried out within notified forest area. Google earth coterminous data was also used for reference. Accuracy assessment was done using random points generated using ERDAS Imagine in addition to the field data equally distributed in all the density classes. Error matrix or confusion matrix for the same was calculated and overall accuracy of, 93\% was achieved. The Kappa coefficient was approximately 0.92 , which shows the quality and accuracy of the FCD model.

Table 2. Shows that maximum forest area is under FCD category of 60 to $80 \%$ comprising 17382.6 acres of area, which is $40.3 \%$ of total notified forest area in Yamunanagar district. Around 24.2\% (10423.9 acres) area is under scrub land and open forest category which need to be focused for plantation. $26.8 \%$ (11548.48 acres) area is under moderately dense forest. $8.8 \%$ (3978.45 acres) area is under highly dense forest in Yamunanagar district which mostly comes under Kalesar forest range.

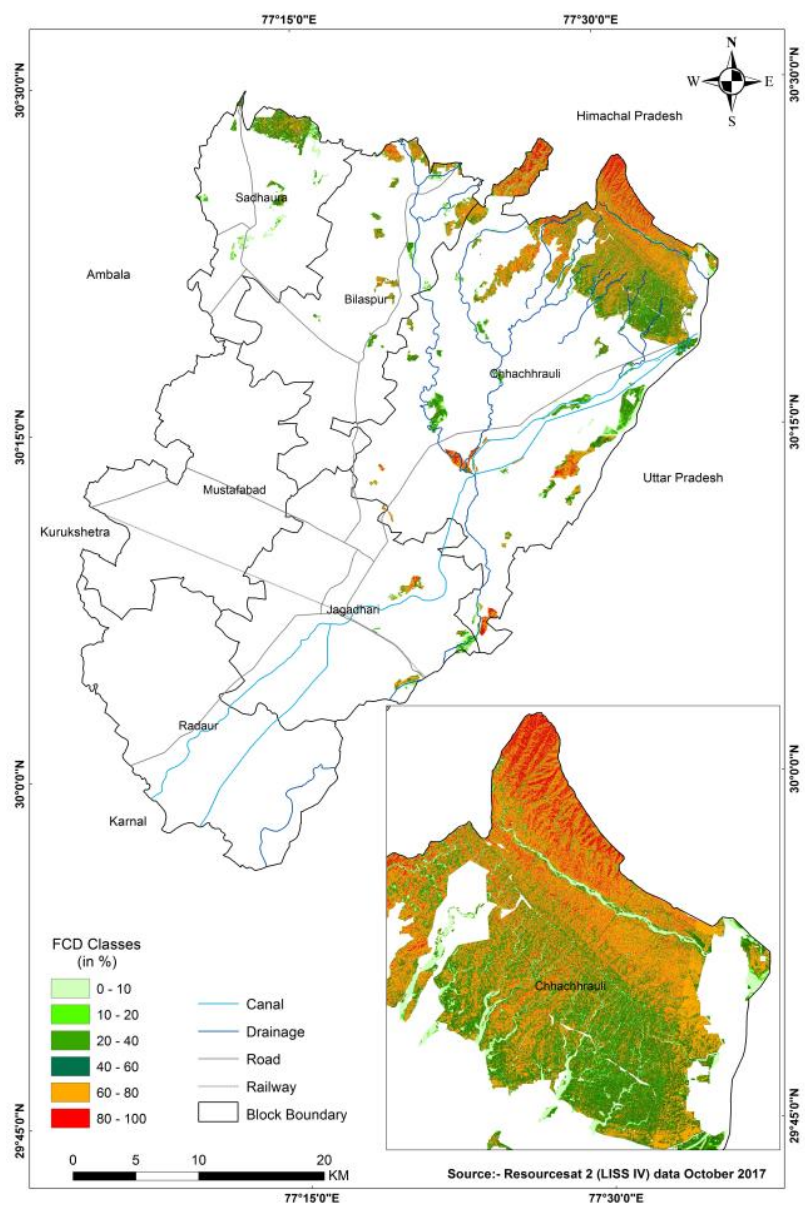

Figure 3. Forest Canopy Density map of Yamunanagar district

\begin{tabular}{|c|l|l|c|c|}
\hline S No. & \multicolumn{2}{|c|}{ FCD Class } & $\begin{array}{c}\text { Area } \\
\text { acres })\end{array}$ & $\begin{array}{c}\text { Area } \\
(\%)\end{array}$ \\
\hline 1 & Scrub land & $<10 \%$ & 4745.90 & $11.0 \%$ \\
\hline 2 & Open Forest-I & $10-20 \%$ & 1203.59 & $2.8 \%$ \\
\hline 3 & Open Forest-II & $20-40 \%$ & 4474.41 & $10.4 \%$ \\
\hline 4 & Moderately Dense & $40-60 \%$ & 11548.48 & $26.8 \%$ \\
\hline 5 & Medium Dense & $60-80 \%$ & 17382.61 & $40.3 \%$ \\
\hline 6 & Highly Dense & $>80 \%$ & 3798.45 & $8.8 \%$ \\
\hline
\end{tabular}

Table 2. Gives category wise area of Forest Canopy Density

Figure 4. Shows that maximum area is under Medium Dense Forest and minimum area is under Open Forest-I (10-20\% FCD). Out of total geographic area in Yamunanagar district only $10 \%$ is forest and out of this approximately $67 \%$ (28931.08 acres) comes under moderately dense and Medium Dense forest i.e. $40-80 \%$ FCD category.

Figure 5. Show the spatial locations of areas with low forest density (FCD $<40 \%$ ) within the forest boundary. These are the main areas where maximum effort should be taken to improve the canopy cover. This information is based on per pixel FCD calculation having dimension of 5 meter $\mathrm{x} 5$ meter. 


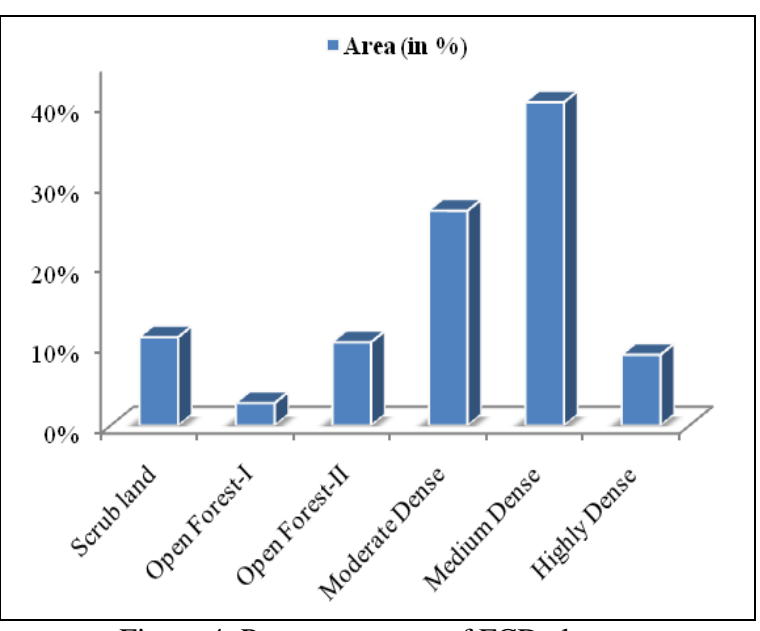

Figure 4. Percentage area of FCD classes

At 1:10,000 (large scale) map, this information is very useful for forest department to improve and manage the forest areas. It is clear from figure 5 that generally areas at lower altitude need more attention for increasing forest canopy density.

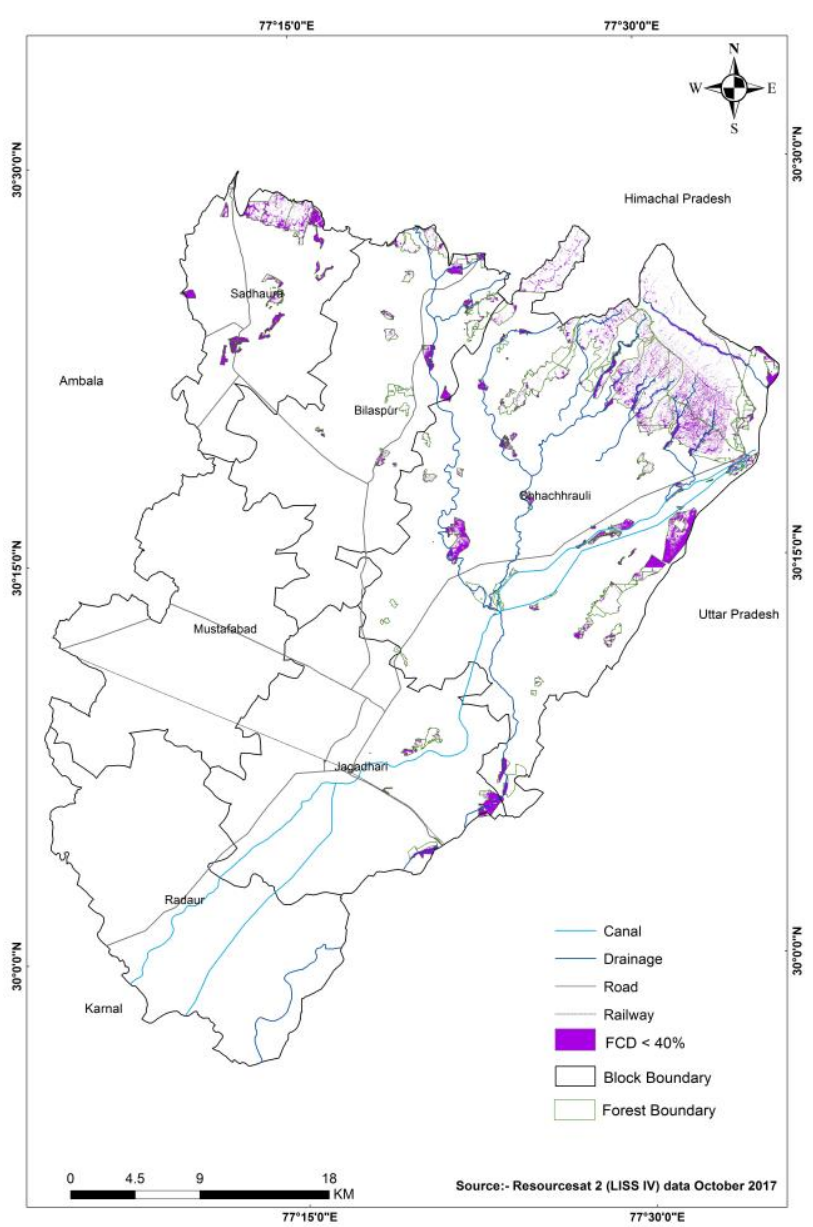

Figure 5. Area having FCD less than $40 \%$

\section{CONCLUSION}

Since the assessment was done on large scale $(1: 10,000)$, it is very useful for planning and management of forest resources in the district. Also repetitive analysis will help in monitoring the changes in the forest. This method is quick and is very useful for areas which are not accessible on ground.

\section{ACKNOWLEDGEMENT}

Funding for this project was provided by Haryana Forest Department. The help provided by DFO and other forest officers for field validation and reaching deep within the forest is also acknowledged.

\section{REFERENCES}

Azizia, Z., Najafi, A., and Sohrabia, H., 2008. Forest canopy density estimating using satellite images. Proc. of the International Society for Photogrammetry and Remote Sensing Congress Commission VIII, Beijing, China.

Fiala, A.C.S., Garman, S.L., Gray A.N., 2006. Comparison of five canopy cover estimation techniques in the western Oregon Cascades. Elsevier

Haryana Forest Department 2006. http://haryanaforest.gov.in/en-us/About-us/Vision

Huang C., Yang L., Wylie B., Homer C. (2001): A strategy for estimating tree canopy density using Landsat 7 ETM+ and high resolution images over large areas. Available at http://landcover.usgs.gov/pdf/canopy_density.pdf

Korhonen, L., Korhonen, K.T., Rautiainen, M., Stenberg P., 2006. Estimation of forest canopy cover: A comparison of field measurement techniques. Silva Fennica, 40, pp. 577-587.

Ministry of Enviornment, Forest and Climate Change,1988 http://envfor.nic.in/about-ministry/about-ministry

Mothi Kumar. K.E., Singh, S., Attri, P., Kumar, R. , Kumar, A., Sarika., Hooda, R.S., Sapra R.K., Garg, V., Kumar, V. and Nivedita, 2014. Gis based cadastral level forest information system using World View-2 data in Bir Hisar (Haryana). In: The International Archives of the Photogrammetry, Remote Sensing and Spatial Information Sciences, Volume XL-8. 605612 .

Rikimaru, A., 1999. The concept of FCD mapping model and semi-expert system. FCD mapper user's guide. International Tropical Timber Organization and Japan Overseas Forestry Consultants Association. Pp 90.

Sharma, A. R., Badarinath, K.V.S., and Roy, P.S., 2008. Corrections for atmospheric and adjacency effects on high resolution sensor data -A case study using IRS-p6 LISS-IV data. In: The International Archives of the Photogrammetry, Remote Sensing and Spatial Information Sciences. Vol. XXXVII. Part B8. Beijing, pp.497-502. 